\title{
Norma versus Subjetividade: o legado de Canguilhem
}

\author{
Maria Elisa F. G. Campos \\ Doutora e Mestre em Psicologia na área de Estudos Psicanalíticos pela Universidade Federal de \\ Minas Gerais. \\ Especialista em Saúde Mental pela Escola de Saúde de Minas Gerais e em Direito Público pelo \\ Unicentro Newton Paiva. \\ Professora do IBMEC-MG. Psicóloga judicial do Programa PAI-PJ - TJMG e psicanalista \\ correspondente da Escola Brasileira de Psicanálise - Seção MG. \\ elisafgcampos@yahoo.com.br
}

\section{Resumo}

O presente trabalho é fruto de uma discussão proveniente da tese de doutorado intitulada $D a$ classificação ao diagnóstico: o psicopata entre a norma e a subjetividade (Campos, 2014). Nesse recorte, buscou-se apresentar as contribuições de Georges Canguilhem sobre a noção de norma, o que permite ler a crescente busca contemporânea pelas classificações. $O$ ensino do referido médico e também a de Foucault, seu orientando, servem como substrato para verificar que os manuais diagnósticos atuais cada vez mais se sustentam na tentativa de normatização e enquadramento dos sujeitos. Após percorrer o legado deixado por Canguilhem, buscando contextualizá-lo, o artigo questiona essa tendência normativizante, através de uma leitura psicanalítica que inclui o dado da subjetividade. Esta leitura coloca em evidencia a relevância clínica de se levar em conta exatamente o que está fora da norma e que pode se referir a um modo particular de gozo.
\end{abstract}

Palavras-chave: norma, subjetividade, Canguilhem, diagnóstico, classificação.

\section{Norme versus Subjectivité : I'héritage de Canguilhem}

Ce travail est le résultat de la discussion proposée dans la thèse de doctorat intitulée De la classification au diagnostic : le psychopathe entre la norme et la subjectivité (Campos,2014). Dans cette perspective, l'objectif est de présenter les contributions de Georges Canguilhem sur la notion de norme, qui permettent de mieux comprendre l'effort contemporain de faire des classifications. Les formulations de ce médecin et également celles de Foucault, dont il fut le directeur de thèse, ont bien servi de substrat pour vérifier le fait que les manuels de diagnostic actuels tiennent de plus en plus à la tentative de réglementation et à l'encadrement des sujets. Après avoir parcouru le travail légué par Canguilhem, cherchant à le contextualiser, cet article met en question cette tendance normativisante à travers une lecture psychanalytique comprenant les données de la subjectivité. Cette lecture met en évidence la pertinence clinique de prendre en compte exactement ce qui est en dehors de la norme et ce qui peut se référer à une façon particulière de jouissance.

Mots clés: norme, subjectivité, Canguilhem, diagnostic, classification.

\section{Norm versus Subjectivity: the legacy of Canguilhem}

The present work is an outgrowth of a discussion originated from the doctor degree thesis entitled "From the classification to the diagnosis: the psychopath from the norm to the subjectivity" (Campos, 2014). On this snippet, we have sought to present the contributions of Georges Canguilhem concerning the norm, which allow us to comprehend the contemporary augmentation of the search for classifications. The formulations of the referred physician and also of Foucault's, his pupil, serve as the foundation to verify that the current diagnostic manuals are sustained on the increasing attempt of normalization and framing of the individuals. After traveling through the legacy left by Canguilhem, seeking to put it into context, the article questions this normative tendency from the perspective of the psychoanalytical view that includes the subjectivity element. This interpretation highlights the clinical 
relevance of including precisely what is left outside the norm and what can be referred as a particular form of joy (jouissance).

Keywords: norm, subjectivity, Canguilhem, diagnosis, classification.

\title{
Norma versus Subjetividade: o legado de Canguilhem ${ }^{1}$
}

\author{
Maria Elisa F. G. Campos
}

Para que seja possível avançarmos na investigação sobre a questão dos diagnósticos no campo do mental, torna-se essencial a problematização das noções de normal e patológico, nessas ciências. Com Canguilhem (1963/2010, p. 199), pode-se identificar que o conceito de normal se popularizou e se naturalizou a partir do vocabulário de duas instituições: a instituição pedagógica e a instituição sanitária. Em que nos interessa essa consideração do autor? São justamente essas duas instituições as que mais prezam pelo enquadramento do sujeito em determinados padrões de condutas e que acabam por excluí-lo ao prescreverem sua segregação ou tratamento, seja este medicamentoso ou de adaptação social.

Nossa pesquisa se interessa por essa discussão, uma vez que trabalha com a perspectiva de que determinadas classificações nosológicas dos manuais diagnósticos psiquiátricos - DSM e CID acabam por reforçar a exclusão da subjetividade, operando a favor de uma universalização, da qual o sujeito, em sua definição psicanalítica - que veremos posteriormente -, escapa em sua divisão.

É importante ressaltar que há uma adequação que se espera dos sujeitos para com a norma. Entretanto, se trabalhamos com o viés da psicanálise, faz-se necessário estabelecer um paralelo entre essas duas noções: norma e subjetividade. No presente artigo, buscaremos trazer os preceitos em relação a essas duas noções, buscando trazer elementos que permitam um avanço no debate atual sobre os diagnósticos no campo do mental. As contribuições de Canguilhem e de Foucault servem-nos como substrato para verificar que as classificações, tal qual aparecem nos manuais diagnósticos contemporâneos, ainda se baseiam numa normatização, isto é, na tentativa de enquadramento dos sujeitos à norma social vigente. Se na psicanálise sabemos que aquilo que o sujeito tem de mais particular é exatamente o que está fora da norma ou de um enquadre - o gozo -, como podemos contribuir para esse debate? Iniciaremos pela noção de norma para, em seguida, trazermos os aspectos relevantes à questão da subjetividade.

\section{Georges Canguilhem e a norma}

Canguilhem (1904-1995) foi filósofo, médico e cientista francês. O autor teve, desde o início de sua vida escolar e acadêmica, um destacado desempenho, sendo notório o seu brio intelectual. Após lecionar em diversos liceus na França, inclusive em Toulouse, Canguilhem iniciou seus estudos sobre a medicina. Os motivos para tal empreitada passam por uma certa decepção com a filosofia, mas, acima de tudo, por uma necessidade de confrontar-se "com uma experiência concreta, um 'campo', uma disciplina que, sem ser científica, permitisse dar corpo e vida à reflexão conceitual" (Roudinesco, 2007, p. 22). 
Apesar de muito engajado politicamente, o teórico não deixou de lado as suas aspirações acadêmicas, escrevendo e defendendo, em julho de 1943, ou seja, em pleno conflito mundial, sua tese de doutorado em medicina sobre o normal e o patológico. Publicada no mesmo ano, tornou-se sua obra mais célebre e referência até hoje sobre o assunto².

Foucault, que foi orientado por Canguilhem em sua tese de doutorado, trabalho que deu origem à obra clássica História da loucura na Idade Clássica (2010), escreveu o seguinte sobre o mestre:

Eliminem Canguilhem, e vocês deixarão de entender muita coisa de toda uma série de discussões que tiveram lugar entre os marxistas franceses; não saberão também o que há de tão específico em sociólogos como Bordieu, Castel, Passeron, e o que os marca tão intensamente no campo da sociologia; perderão todo um aspecto do trabalho teórico realizado pelos psicanalistas, em especial os lacanianos. E mais: em todo o debate de ideias que precedeu ou seguiu o movimento de 1968, é fácil descobrir o lugar daqueles que de perto ou de longe, foram formados por Canguilhem. (cf. Roudinesco, 2007, p. 13)

Feito esse breve preâmbulo histórico, podemos dizer que Canguilhem tem o mérito de ter trabalhado extensivamente o conceito de norma no livro O normal e o patológico (1943). Dessa maneira, o tomaremos como referência para a desconstrução da classificação do diagnóstico que, em nossa tese, utilizamos como paradigmático o de psicopatia, atualmente nomeado "transtorno de personalidade antissocial".

O filósofo e médico inicia a obra em questão comentando três importantes autores da filosofia e da medicina: Auguste Comte, Claude Bernard e René Leriche, destacando a contribuição de cada um na posterior discussão que se fará em relação ao problema do normal e do patológico.

\section{As contribuições de Comte, Bernard e Leriche}

Augusto Comte (1798-1857) foi fundador da sociologia e do positivismo, ciência que considera a necessidade de ver para prever, a fim de prover. Canguilhem abordará este autor a partir do "princípio de Broussais" (1828), por ter atribuído a este último o mérito de ter proclamado que todas as doenças aceitas como tal são apenas sintomas. Canguilhem nos adverte que Broussais demonstrou que os fenômenos da doença coincidem essencialmente com os fenômenos da saúde, dos quais só se diferenciam pela intensidade.

Considerando que tanto Comte quanto Broussais avaliam o conceito de normal e patológico pelo dado do excesso ou da falta de excitação, Canguilhem conclui que se trata aí de um caráter quantitativo e normativo, dissimulado sob uma pretensão métrica. $E$, é em relação a uma medida considerada válida e desejável, ou seja, em relação a uma norma, que se pode falar em excesso ou falta. Portanto, definir o normal por meio do que é de mais ou de menos é reconhecer o caráter normativo do estado dito normal. 
Claude Bernard (1813-1878), médico e fisiologista francês, ainda lembrado por ter criado a medicina experimental, lança as bases para nossa atual medicina baseada em evidências. Para Claude Bernard, a saúde e a doença não são modos de funcionamento que difiram essencialmente. Há uma continuidade entre o normal e o patológico, assim como se dá em relação à vida e à morte. As conclusões de Claude Bernard e de sua medicina experimental ampliam a discussão sobre o normal e o patológico ao considerar que o fisiológico e o patológico se confundem, sendo uma única e mesma coisa, ou seja, o patológico se distingue do normal apenas em gradação. Canguilhem concluirá seu estudo sobre o citado autor avaliando a dignidade do sintoma para exprimir a situação de um adoecimento, mas considerando-o dentro do contexto de um indivíduo, e não apenas um pedaço de corpo. Assim, ressalta que a clínica coloca os médicos em contato com indivíduos completos e concretos, e não com seus órgãos e funções (Canguilhem, 1943, p. 54). Após ter estudado a concepção de um filósofo (Comte) e a de um cientista (Bernard), Canguilhem se debruça sobre a arte da clínica praticada por um técnico: René Leriche.

René Leriche (1879-1955) foi um famoso cirurgião francês. Canguilhem se utilizará de sua referência em contraposição aos dois autores comentados anteriormente: Comte e Bernard. Será Leriche quem dará a mais clara definição da noção de saúde por nós visitada: "saúde é vida no silêncio dos órgãos". Inversamente, a "doença é aquilo que perturba os homens no exercício normal de sua vida e em suas ocupações e, sobretudo, aquilo que os faz sofrer" (Canguilhem, 1943, p. 57). Mas o importante a considerar, do ponto de vista de Leriche, é tomar a doença a partir do sujeito, e não do médico. Será o paciente quem dirá e terá um saber sobre seu estado e não o médico.

Tomando as reflexões de Leriche, Canguilhem considerará que a noção de normal que se tem depende da possibilidade de infrações à norma. Para Leriche, a doença não será tratada como uma modificação quantitativa nos fenômenos fisiológicos ou normais e, sim, como um estado autenticamente anormal. O filósofo-médico segue com esse desenvolvimento, a ponto de nos fazer pensar nas patologias do mental, ao afirmar que as doenças são novos modos de vida. Com essa consideração, podemos pensar nas psicopatologias que aparecem nas classificações como tentativas de cada sujeito de se inscrever na vida, ao seu modo. Podem ser manifestações sintomáticas que dizem respeito a um funcionamento específico daquele sujeito. Parece ser essa a orientação de Leriche: ouvir o adoecimento a partir do sujeito, e não do saber que o médico acredita ter sobre ele. Leriche não se orienta pelo a priori da teoria, buscando encontrar os elementos de sua técnica na fala do paciente, e não no saber do médico ou de sua teoria.

\section{Correlações do normal e do mental em Canguilhem}

Na segunda parte do livro de Canguilhem, encontramos a correlação dos conceitos de normal e patológico com o campo do mental. O autor recorre a psiquiatras como Jaspers, Lagache e Henry Ey para nos mostrar que o mental pode trazer contribuições à discussão sobre a norma. Ressalta o valor clínico do sintoma ao se analisar um quadro psicopatológico, alegando que, muitas vezes, ele pode trazer elementos novos que fogem à norma ou à vida psíquica dita normal. 
Canguilhem cita Lagache, lembrando-nos que, quando um paciente é classificado como alienado, os psiquiatras não agem como "especialistas", mas, sim, "como homens", incluindo-se aí a subjetividade e os valores daquele que diagnostica. $\mathrm{O}$ autor vai além, quando afirma que "o alienado não se enquadra, não tanto em relação aos outros homens, mas em relação à própria vida; não é tanto desviado, mas sobretudo diferente" (Canguilhem, 1943, p. 79). O médico-filósofo remete-se também a Minkowiski para nos advertir quanto ao fato de que é pela anomalia que o ser humano se destaca do todo formado pelos homens e pela vida. É ela que nos revela o sentido de uma maneira de ser inteiramente "singular" (Canguilhem, 1943, p. 79). Para Minkowiski, há na anomalia o primado do negativo, sendo que aí o mal se destaca da vida, ao passo que o bem se confunde com o dinamismo vital. Nesse debate, Canguilhem também visita Goldstein, para com ele afirmar que, em matéria de patologia, a norma é, antes de tudo, individual. Retorna em seguida a Minkowiski para alegar que "o normal não é uma média correlativa a um conceito social, não é um julgamento de realidade, é um julgamento de valor, é uma noção-limite que define o máximo de capacidade psíquica de um ser. Não há limite superior da normalidade" (Canguilhem, 1943, p. 80).

O médico segue nessa discussão, apoiando-se agora em Jaspers, ao reconhecer que, em relação aos diagnósticos, mais do que a opinião dos médicos, será a apreciação dos pacientes e das ideias dominantes do meio social que vão determinar o que se chama de "doença" (Canguilhem, 1943, p. 83, itálicos nossos). Canguilhem dirá que se trata de um julgamento de valor virtual, e, ainda, que estar doente significa ser nocivo ou indesejável, ou socialmente desvalorizado. Essa definição se encaixa perfeitamente em nossa discussão sobre o diagnóstico de transtorno de personalidade antissocial, pois, como já diz a própria classificação, há algo aí que não se socializa. Sabemos pela psicanálise que o que não se socializa é o modo de gozo e que as vias de tratamento deverão levar em conta isso, que é do campo da subjetividade, para o compromisso com o laço social.

Para concluir essa abordagem que aproxima o campo do mental ao do biológico, em se tratando de normas, Canguilhem nos dirá que o que interessa ao médico é diagnosticar e curar, sendo que curar é fazer voltar à norma uma função ou um organismo que dela tenha se afastado, considerando que esse trabalho leva em conta a representação comum da norma em um meio social, em dado momento.

\section{Sobre os conceitos de normal e anormal}

Será vinte anos mais tarde, em sua obra Novas reflexões referentes ao normal e ao patológico (1966), que Georges Canguilhem retomará a discussão anterior referente ao normal e ao patológico, afirmando que a razão da finalidade e do uso polêmico do conceito de norma deve ser procurada na essência da relação normal-anormal. Assim, ressalta que:

(...) uma norma se propõe como um modo possível de unificar um diverso, de reabsorver uma diferença, de resolver uma desavença (...). Com efeito, uma norma só é a possibilidade de uma referência quando foi instituída ou escolhida como expressão 
de uma preferência e como instrumento de uma vontade de substituir um estado de coisas insatisfatório por um estado de coisas satisfatório. Assim, qualquer preferência de uma ordem possível é acompanhada - geralmente de maneira implícita - pela aversão à ordem inversa possível. O oposto do preferível, em determinado campo de avaliação, não é o indiferente, e sim aquilo que é repelente ou, mais exatamente, repelido, detestável. (Canguilhem, 1966/2010, p. 202, itálicos nossos)

Ora, toda essa discussão se coaduna com aquela relativa aos diagnósticos no campo da saúde mental, por exemplo, quando se trata de tentar avaliar um sujeito a partir de seu ato criminoso. Diante do repelível de um ato, do detestável quanto a admitir que a natureza criminosa também pode ser humana, somos levados a restabelecer a ordem, lançando esses indivíduos para o campo fora do convívio, ou fora do campo da normalidade. Certamente não são atos facilmente assimiláveis e tentamos, com a categorização em classificações orientadas pela norma, além de dar sentido ao semsentido do ato, distinguirmo-nos desses sujeitos (criminosos).

Retornando à obra de Canguilhem, verificamos que este conclui que "as normas só são reconhecidas como tal nas infrações" (Canguilhem, 1966/2010, p. 158). O autor dirá que, na ordem do normativo, o começo é a infração; seja esta infração no campo biológico ou mental, será preciso chamar à regularidade e à norma isso que the escapa. Se, para Leriche, como já citado, saúde é vida no silêncio dos órgãos, no campo do laço social, a saúde mental pode ser lida como vida na discrição das relações sociais. Tudo que aparece em excesso ou demasia poderá convocar a interpretação da necessidade de regulação ou de contenção, como a da adequação à norma.

Canguilhem se remete à semântica da palavra normal, respaldado pelos dicionários de medicina de Littré e Robin (1873), bem como pelo de filosofia de Lalande (1938). De acordo com o primeiro, normal vem de normalis e significa o que é conforme a norma, regular. Do segundo, ele toma a ambiguidade apontada pelo autor da palavra normal, que também pode ser conforme a norma ou a regra, mas esta será estabelecida por um valor atribuído por aquele que fala, em virtude de um julgamento de apreciação. Para esse filósofo, a própria vida em si mesma faz do conceito de normal um valor. No pleno sentido da palavra, normativo é o que institui as normas.

A anomalia é um substantivo ao qual não corresponde nenhum adjetivo e, inversamente, anormal é um adjetivo sem substantivo, de modo que o uso os associou, fazendo do anormal o adjetivo de anomalia. No entanto, as origens das palavras anormal e anomalia são radicalmente distintas. Anomalia vem de omalo, que, em grego, quer dizer uniforme, regular, liso. O sentido de anomalia seria, então, o de desigual, rugoso, irregular. Alguns dicionários contribuíram para o equívoco, atribuindo a origem da palavra não a omalos e, sim, ao nomos (lei), grego, e à norma, latim, palavras que têm por característica a propriedade de se misturarem. Assim, rigorosamente falando, anomalia designa um fato, sendo um termo descritivo. Por sua vez, anormal faz referência a um valor e é um termo apreciativo, normativo. 
Canguilhem prossegue em sua argumentação até nos mostrar que diversidade não é doença e que, de certa forma, somos todos anômalos. Ele trabalha com a noção de que a anomalia é consequência da variação individual, que impede dois seres de poderem se substituir de modo completo. Ele nos dirá que o anormal não é o patológico e que a saúde perfeita e contínua é um fato anormal (Canguilhem, 1966/2010, p. 96). Sua obra nos leva a ver que não existe um fato que seja normal ou patológico em si e a normalidade advém da normatividade. Com essas contundentes argumentações, o autor vai desconstruindo todos os sentidos coloquiais dos termos saúde, doença, normal, anomalia, para valorizar a multiplicidade das formas da vida e a variabilidade individual. Não é por acaso que Canguilhem tenha sido tão caro, como é sabido, a Jacques Lacan.

Para seguirmos as vias de Canguilhem e avançarmos em nossa discussão, não podemos nos esquecer aqui da importante contribuição de Michel Foucault, um dos mais eminentes orientandos de Canguilhem, com seu seminário dos anos 1974-1975, no Collège de France, sobre o tema dos anormais.

\section{Os anormais, segundo Michel Foucault}

No seminário publicado sob o título Os Anormais (1974-1975/2001), Michel Foucault, a partir de múltiplas fontes teológicas, jurídicas e médicas, aborda o problema dos indivíduos perigosos que, no século XIX, esteve muito associado ao domínio da anormalidade. Entre os anormais estavam os chamados "monstros", figuras que adquiriram várias facetas, a depender do contexto histórico. Foucault nos mostra que há uma arqueologia da anomalia, sendo que o anormal seria descendente de três indivíduos: o monstro, o incorrigível e o masturbador.

Embora Foucault perpasse toda uma galeria de monstros, há aquele que se destaca e é mais largamente trabalhado pelo autor: o monstro moral. Este se delineia no século XIX, tendo como característica essencial possuir uma natureza criminosa intrínseca. 0 monstro moral traz consigo o "labirinto jurídico" e conduz ao engate de duas maquinarias e suas engrenagens, a partir da noção de instinto: o mecanismo penal e o mecanismo psiquiátrico.

Com a leitura de Os anormais é possível verificar que foi a noção de instinto, trazida pela psiquiatria ao mecanismo jurídico-penal, que fez com que se pudesse transformar, com roupagens científicas, a ausência de razão de um ato criminoso num mecanismo patológico positivo. Cria-se, assim, um diagnóstico como foi o da monomania homicida ${ }^{3}$ - podemos pensar também naquele do transtorno de personalidade antissocial -, a partir do vazio de sentido que aparece quando se está diante de um grande acontecimento criminal. Em outras palavras, nos diz Foucault, na falta do delírio, na falta de demência, na falta de alienação, a psiquiatria recorre ao instinto (1974-1975/2001, p. 175). Ela se desloca dos mecanismos patológicos positivos para o comportamento do criminoso, isso ainda no século XIX.

Os desdobramentos que se verificam na arqueologia foucaultiana, que vão do anormal ao monstro e sua vinculação com o instinto, nos fazem chegar à atualidade para pensarmos no grande fato criminal e nos indagarmos: o que mudou do século XIX até os dias atuais em relação a essa conceituação do monstro? Não 
estamos ainda diante do monstro moral, quando utilizamos determinadas classificações como as de psicopata ou de transtorno de personalidade antissocial? É impressionante verificar com Foucault como o problema do monstro não ficou contido nos anos do século XIX, tampouco a noção de instinto. O grande acontecimento criminal continua nos deixando sem palavras para significar o que tenha sido $o$ ato criminoso. Foucault afirma que denominar o inexplicável pelo monstruoso esvazia, em certo sentido, a falta de significação para esse fato, que pode ser um crime imotivado.

Evidenciamos assim que podemos encontrar em Os anormais as bases de conceituações que vão sendo construídas para fundamentar diagnósticos, como o que estamos utilizando como paradigmático: a psicopatia ou o Transtorno de Personalidade Antissocial. Diante da falta de sentido de um ato criminoso, muitas vezes bárbaro, resta-nos o real e pouco recurso simbólico para nomear o que seja essa contranatureza na natureza do humano. Gostaríamos aqui de demarcar quão relevante se torna esse giro que se opera nas funções da psiquiatria desde o seu surgimento até hoje, para encontrarmos os elementos que nos permitam pensar na confecção de determinados diagnósticos em saúde mental em nossos dias.

Uma constatação que podemos fazer é a de que, à medida que nos afastamos da clínica e recorremos às estatísticas e à previsibilidade de ações, nos distanciamos cada vez mais da possibilidade de dar um tratamento a isso que retorna no real, como pode ocorrer em casos de cometimento de crimes na psicose.

\section{A psicanálise e a subjetividade}

A experiência na clínica com casos de psicose ${ }^{4}$ nos permite encontrar o dado clínico na tessitura do diagnóstico, para além da norma ou do enquadre em uma classificação psiquiátrica contemporânea, conforme preveem os manuais. O que se pode observar é que nos casos de cometimento de crimes graves, encontra-se o dado subjetivo, a trama pulsional que subjaz por detrás do ato. Nessa prática, é possível constatar que a subjetividade escapa à avaliação classificatória das perícias ou ainda às constantes buscas de um determinante biológico que justifique a atuação criminosa - tal como ocorria no século XIX com a antropologia criminal e retorna atualmente com as pesquisas das neurociências. $O$ legado freudiano e a sua teoria da pulsão de morte se reavivam no fato criminoso e é por esse motivo que de sua orientação não se pode prescindir. De acordo com Miller (1988), a consideração metódica do sujeito é o que há de novo para a psicanálise, sendo também o que pode orientar a posição clínica dos que com ela operam. Será essa postura ética o que vai demarcar a posição daquele que escuta um caso, não por uma apresentação fenomenológico-comportamental, mas levando em consideração que o sujeito em questão precisa ser levado em conta por aquele que atende, diagnostica, pericia, acompanha etc.

Em nossa tese (Campos, 2014), trabalhamos alguns casos de sujeitos que cometeram crimes e que nos levaram à construção do diagnóstico de psicose, juntamente com nossos autores de referência. Visitamos também autores das neurociências e as discussões atuais sobre a classificação do transtorno de personalidade antissocial. Retornando a Freud em sua I Conferência Introdutória à Psicanálise 
(1915-1916/1980), pudemos verificar que a ciência realmente rejeita para fora do seu campo de interesse o dado da subjetividade ao tentar incluir, automaticamente, na categoria do transtorno de personalidade antissocial os sujeitos que cometem crimes graves. Entretanto, a construção dos casos nos levou a encontrar o dado subjetivo, o elemento da foraclusão que apontava para casos de psicose, revelando um modo particular de gozo desses sujeitos e não apenas um transtorno de personalidade antissocial. Dessa maneira, apostando na clínica e na orientação da psicanálise, é possível sustentar um trabalho para além da classificação, buscando, inclusive, construir com o sujeito a possibilidade de responsabilização pelo ato cometido.

\section{Conclusão}

As contribuições de Canguilhem e de Foucault servem-nos como substrato para verificar que as classificações, tal qual aparecem nos manuais diagnósticos contemporâneos ainda se baseiam numa normatização, isto é, na tentativa de enquadramento dos sujeitos à norma social vigente. Se, a partir da psicanálise, sabemos que aquilo que o sujeito tem de mais particular é exatamente o que está fora da norma ou de um enquadre - o gozo -, como podemos contribuir para esse debate? A experiência com os casos de psicose nos faz ver que, para além do ato, subsiste um sujeito que dele se utiliza para, muitas vezes, tentar dar um tratamento ao real da foraclusão.

Biagi-Chai (2014) nos diz que, na contemporaneidade, encontramos, na política e no discurso modernos, uma destituição da função da palavra e, concomitantemente, uma negação crescente da loucura. Essa situação, de acordo com a autora, conduz a um "empuxo ao ato" frente ao discurso moderno. Na ausência da palavra, o que encontramos não é exatamente a passagem ao ato? Essa é a lição de Lacan em seu seminário de 1962-1963: o ato vem no lugar de um dizer.

Podemos constatar, nas sucessivas edições dos DSMs, uma proliferação de categorias nosológicas e também o desaparecimento das estruturas clínicas em favor de descrições fenomenológico-comportamentais. Nossa tese se coaduna com a de Biagi-Chai e é a de que a loucura não escapa a essa "foraclusão" e cede lugar aí aos "transtornos de personalidade", onde ocorre a criação de categorias tipificadas para dar conta de passagens ao ato, de crimes. Apostamos na palavra como único instrumento capaz de incluir e implicar sujeito e ato, não se excetuando, é claro, a responsabilização por este. A classificação se produz atualmente sem que haja uma "discriminação subjetiva", isto é, sem saber quem é aquele que se porta assim, sendo que essa é a única chance de se ter uma ideia sobre isso que insiste como ato para um determinado sujeito (Biagi-Chai, 2014).

A destituição da função da palavra pode ter efeitos catastróficos para o corpo social. Ainda de acordo com Biagi-Chai, se, numa classificação, a certeza está do lado daquele que escuta, este é o reino do pré-julgamento. Se este é colocado a serviço de uma vontade política ou de outro poder estabelecido, encontra-se o totalitarismo, com o desaparecimento daquele que fala e sua redução a objeto. Na psicanálise, o objeto é, antes, a própria palavra e nos serve de orientação clínica, é aquele que possibilita o acesso às perturbações de linguagem ou ao falasser. 
Marie-Helène Brousse (2009, p. 10) nos adverte que no tempo do Outro que não existe, estamos vivendo a realidade do Nome-do-Pai foracluído do simbólico que retorna no real. Ela se fundamenta em Lacan (1973-1974) ao afirmar que esse Nome-do-Pai (NP) foracluído retorna como normas sociais no discurso. Esse discurso se torna supersocial e se transforma em uma ordem de ferro que não tem como correlato o desejo e, sim, o gozo. E, quando o NP se transforma em cifra, só o supereu pode responder. Ela o nomeia de supereu estatístico, sendo que as estatísticas aí deixam de ser tratadas como probabilidades para assumirem valores de certeza. A discussão que fizemos sobre a transformação do diagnóstico de psicopatia em Transtorno de Personalidade Antissocial ${ }^{5}$ só faz confirmar essas alegações, sendo um correlato das estatísticas o teste de personalidade criado para classificar e segregar esses sujeitos classificados como antissociais ${ }^{6}$. As políticas que podem advir desse discurso, com vestes científicas, são temerárias e caminham rumo ao pior.

Diante de tão contundentes argumentos, resta-nos a política da psicanálise para estar à altura de seu tempo (Lacan, 1967) ao se imiscuir nas instituições com seu discurso "não-todo", pois é aquele que suporta o furo do simbólico e que restitui ao sujeito a palavra como forma de tratamento e de humanização.

\section{Notas}

${ }^{1}$ Este trabalho é fruto da discussão realizada durante a defesa da tese de doutorado Da classificação ao diagnóstico: o psicopata entre a norma e a subjetividade, apresentada na Faculdade de Filosofia e Ciências Humanas da Universidade Federal de Minas Gerais. Belo Horizonte: UFMG, 2014. Agradecemos aqui a valorosa orientação do Prof. Antônio Teixeira.

${ }^{2}$ O Normal e o Patológico (1943) e Escritos sobre Medicina (2005) são as únicas publicações de Georges Canguilhem traduzidas para o português. Além destas, destacam-se: La connaissance de la vie (1952); La formation du concept de réflexe aux XVIIe et XVIIIe siècles (1955); Études d'histoire et de philosophie des sciences concernant les vivants et la vie (1968) e Idéologie et rationalité dans I'histoire des sciences de la vie (1977).

${ }^{3}$ A monomania homicida foi um conceito criado por Esquirol (1772-1840), que inaugurou uma nova modalidade de concepção psiquiátrica de loucura moral, definida no final do século XVII pelo médico Thomas Abercromby, como sendo característica de alguém com bom nível de inteligência, mas com graves defeitos ou transtornos nos seus princípios morais (cf. Fernandes, 1995, p. 69).

${ }^{4}$ Trata-se de minha prática como psicóloga judicial do Programa PAI-PJ.

${ }^{5}$ Essa discussão se encontra trabalhada em nossa tese e no artigo "Diagnóstico e classificação: da ordem simbólica à ordem de ferro". In Coelho dos Santos, T.; Martello, A. \& Santiago, J. (Orgs.). Os corpos falantes e a normatividade do supersocial (pp. 225-255). Rio de Janeiro: Cia de Freud, 2014.

${ }^{6}$ Citamos aqui a Escala Hare, teste criado pelo canadense Robert Hare para dar subsídio à classificação dos chamados psicopatas (em situação de privação de liberdade).

\section{Referências Bibliográficas}

Biagi-Chai, F. (2014). "O empuxo ao ato" do discurso moderno. Responsabilidades - Revista interdisciplinar do Programa de Atenção Integral ao Paciente Judiciário do TJMG, 3(2). Recuperado de http://www.tjmg.jus.br/portal/acoes-e-programas/novos-rumos/pai-pj/revistaresponsabilidades/.

Brousse, M.-H. (2009). A psicose ordinária à luz da teoria lacaniana do discurso. Latusa Digital, 6(38). Recuperado de http://www.latusa.com.br/latusa_revista_digital_38.html. 
Campos, M. E. F. G. (2014a). Da classificação ao diagnóstico: a psicopatia entre a norma e a subjetividade. (Tese de doutorado). Programa de Pós-Graduação em psicologia da Faculdade de Filosofia e Ciências Humanas, Universidade Federal de Minas Gerais.

Campos, M. E. F. G. (2014b). Diagnóstico e classificação: da ordem simbólica à ordem de ferro. In Coelhos dos Santos, T; Martello, A. \& Santiago, J. (Orgs.). Os corpos falantes e a normatividade do supersocial (pp. 225-255). Rio de Janeiro: Cia de Freud.

Canguilhem, G. (2010). O normal e o patológico. Rio de Janeiro: Forense Universitária (Trabalho original publicado em 1943).

Foucault, M. (2001). Os anormais. São Paulo: Martins Fontes (Trabalho original publicado em 19741975).

Freud, S. (1980). Conferência I: parapraxias. Edição standard brasileira das obras psicológicas completas de Sigmund Freud (Vol. 15, pp. 27-37). Rio de Janeiro: Imago (Trabalho original publicado em 1916).

Lacan, J. (2005). O seminário, livro 10: a angústia. Rio de Janeiro: Jorge Zahar (Trabalho original publicado em 1962-1963).

Lacan, J. (2003). Proposição de 9 de outubro de 1967 sobre o psicanalista da Escola. Outros escritos. Rio de Janeiro: Jorge Zahar (Trabalho original publicado em 1967).

Lacan, J. (1973-1974). Le Séminaire, livre XXI: les non-dupes errent. Seminário Inédito.

Miller, J.-A. (1988). Introdução a um discurso do método analítico. FALO - Revista Brasileira do Campo Freudiano, 2(2), 87-96. Salvador: EBP.

Roudinesco, E. (2007). Georges Canguilhem: uma filosofia do heroísmo. Filósofos na tormenta: Canguilhem, Sartre, Foucault, Althusser, Deleuze e Derrida (pp. 13-59). Rio de Janeiro: Jorge Zahar.

Citacão/Citation: Campos, M. E. F. G. (mai. a out. 2014). Norma versus Subjetividade: o legado de Canguilhem. Revista aSEPHallus de Orientação Lacaniana, 9(18), 61-71. Disponível em www.isepol.com/asephallus

Editor do artigo: Tania Coelho dos Santos.

Recebido/Received: 05/09/2013 / 09/05/2013.

Aceito/Accepted: 18/10/2013 / 10/18/2013.

Copyright: (c) 2013 Associação Núcleo Sephora de Pesquisa sobre o moderno e o contemporâneo. Este é um artigo de livre acesso, que permite uso irrestrito, distribuição e reprodução em qualquer meio, desde que o autor e a fonte sejam citados/This is an open-access article, which permites unrestricted use, distribution, and reproduction in any medium, provided the author and source are credited. 